\title{
EVALUATION OF CRACK GROWTH RETARDATION IN BRANCHED FATIGUE CRACKS
}

\author{
Marco Antonio Meggiolaro' \\ Antonio Carlos de Oliveira Miranda² \\ Jaime Tupiassú Pinho de Castro ${ }^{3}$ \\ Luiz Fernando Martha ${ }^{4}$
}

\begin{abstract}
Overload-induced fatigue crack branching (or bifurcation) is a phenomenon capable of inducing significant growth retardation or even crack arrest. Such behavior can quantitatively explain retardation effects even when plasticity induced crack closure cannot be applied, e. g. in high R-ratio or in plane-strain controlled fatigue crack growth. However, the few analytical models available for branched cracks cannot be used to predict the subsequent crack growth nor account for the delays observed in practice. In this work, specialized Finite Element (FE) and life assessment software are used to predict the reduction in the propagation rates in bifurcated cracks. The crack path and the associated stress intensity factors (SIF) of asymmetrically bifurcated cracks are numerically obtained for several bifurcation angles. The companion life assessment program is used to estimate the number of delay cycles associated with crack bifurcation. The proposed approach is validated experimentally, allowing for a better understanding of the influence of crack deflection in the propagation life of structural components.
\end{abstract}

Key-words: fatigue, crack bifurcation, growth retardation.

\section{Avaliação do Retardo de Crescimento por Fadiga de Trincas Bifurcadas}

\section{Resumo}

A bifurcação de trincas causada por sobrecargas é um fenômeno capaz de induzir retardo significativo no seu crescimento subseqüente por fadiga. Esse comportamento pode explicar quantitativamente efeitos de retardo mesmo quando o fechamento da trinca por plasticidade não pode ser usado, e. g. sob altas cargas médias ou sob um estado plano de deformações. Porém, os poucos modelos analíticos disponíveis para trincas bifurcadas não podem ser usados para predizer o seu crescimento subseqüente nem para reproduzir os retardos observados na prática. Nesse trabalho, programas especializados de Elementos Finitos (EF) e de avaliação de vida à fadiga são usados para predizer a redução nas taxas de propagação em trincas bifurcadas. $O$ caminho de trinca e os fatores de intensidade de tensão associados são obtidos numericamente para diversas trincas bifurcadas. $\bigcirc$ número de ciclos de retardo associado à bifurcação é então calculado. Resultados experimentais comprovam a eficiência da metodologia proposta, permitindo uma melhor compreensão da influência desse fenômeno na vida à fadiga de componentes estruturais.

Palavras-chave: fadiga, bifurcação de trinca, retardo de trinca

\section{INTRODUCTION}

It is well known that fatigue cracks can significantly deviate from their mode I growth direction due to the influence of overloads, generating crack kinking or branching (Fig. I). Since the stress intensity factors (SIF) associated to deflected or branched fatigue cracks can be considerably smaller than that of a straight crack with the same projected length, such deviations can cause significant retardation or even arrest of the subsequent crack growth.

It is experimentally observed that very small differences between the branch lengths $\mathbf{b}$ and $\mathbf{c}$ shown in Fig. I are enough to cause the shorter branch to arrest due to shielding effects as the

\footnotetext{
IMechanical Eng., Ph.D., Visiting Professor of the Mechanical Eng. Dept., PUC-Rio

${ }^{2}$ Civil Eng., Ph.D., Tecgraf, PUC-Rio

3Mechanical Eng., Ph.D., Professor of the Mechanical Eng. Dept., PUC-Rio

${ }^{4}$ Civil Eng., Ph.D., Professor of the Civil Engineering Dept., PUC-Rio
} 
larger one propagates, until reaching approximately its preoverload SIF and growth rate (SURESH, 1983a). This typical propagation behavior has been observed in many structural components, e.g. on a branched crack on an aircraft wheel rim made of 2014-T6 aluminum alloy (KOSEC et al., 2002).

It is generally recognized that it is very difficult to develop accurate analytical solutions to the propagation behavior of branched cracks (SURESH, 1983b). Therefore, numerical calculations provided e.g. by Finite Element (FE) or Boundary Element $(B E)$ software are usually the only means to predict such retardation effects.

To predict the propagation path of a branched crack and to calculate its associated modes I and II SIF, a FE program named Quebra2D was developed to simulate 2D fracture processes based on a self-adaptive mesh-generation strategy (MIRANDA et al., 2002). It has been validated through experiments on several modified CT specimens and from comparisons with analytical solutions for kinked cracks. Quebra2D uses three criteria to calculate the crack propagation path in the linear-elastic regime: the maximum circumferential stress $\left(\sigma_{\theta \max }\right)$, the maximum potential energy release rate $\left(\mathbf{G}_{\theta \max }\right)$, and the minimum strain energy density $\left(\mathbf{S}_{\theta \min }\right)$.

The crack path and associated SIF are then exported to ViDa, a general-purpose fatigue design program developed to predict both initiation and propagation fatigue lives under complex loading by all classical design methods (MEGGIOLARO et al., 1998). This life assessment program is used to estimate the number of delay cycles associated with crack bifurcation. In the next sections, these two programs are used to calculate the propagation behavior of bifurcated or branched cracks.

\section{CRACK BIFURCATION PREDICTIONS}

In this section, the Modes I and II SIF are evaluated for cracks of length $\mathbf{a}$ with a small bifurcation of branch lengths $\mathbf{b}$ and $\mathbf{c}(\mathbf{b} \geq$ c) forming an angle 20, see Fig. I. The calculations are performed on a standard $\mathrm{C}(\mathrm{T})$ specimen, FE modeled using Quebra2D assuming width $\mathbf{w}=32.0 \mathrm{~mm}$, crack length $\mathbf{a}=14.9 \mathrm{~mm}$, and bifurcations with initial crack branch lengths $\mathbf{b}_{\mathbf{0}}=10 \mu \mathrm{m}$ and $\mathbf{c}_{\mathbf{0}}=$ $5,7,8,9,9.5$ and IO $\mu \mathrm{m}$. The Modes I and II SIF $\mathbf{k}_{\mathbf{1}}$ and $\mathbf{k}_{\mathbf{2}}$ of each crack branch are obtained for bifurcation angles $2 \theta$ between $40^{\circ}$ and $168^{\circ}$. Note that typical overload-induced bifurcated cracks can have initial branch lengths between 10 and $100 \mu \mathrm{m}$, with $2 \theta$ varying between $30^{\circ}$, e.g. for very brittle materials such as glass, and $180^{\circ}$, e.g. in the vicinity of the interface of a bi-material composite (PIPPAN et al., 2000).

Figure 2 shows the FE results for the SIF $\mathbf{k}_{\mathbf{1}}$ and $\mathbf{k}_{\mathbf{2}}$ (normalized by the Mode I SIF $\mathbf{K}_{\mathbf{I}}$ of the straight crack) of symmetrically bifurcated cracks (which have $b_{0}=c_{0}$ ). The FEobtained $\mathbf{k}_{\mathbf{1}}$ and $\mathbf{k}_{\mathbf{2}}$ and the $\sigma_{\theta \max }$ criterion (MIRANDA et al., 2002) are used to compute an equivalent SIF $\mathbf{K}_{\mathrm{b} 0}$ that will characterize

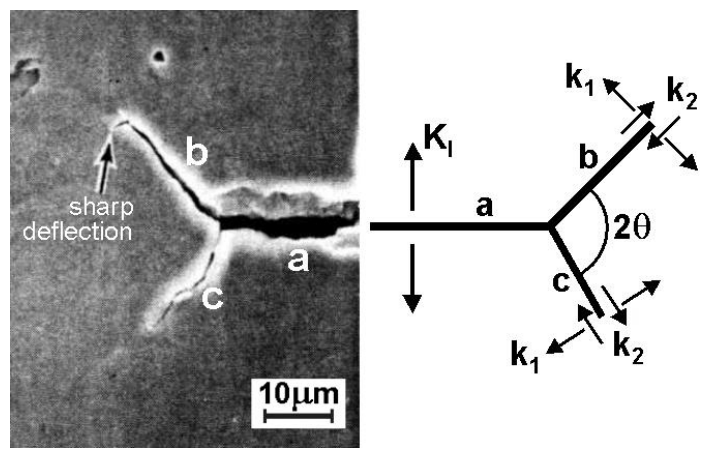

Figura I. Bifurcated crack geometry and nomenclature (LANKFORD et al., I98I).

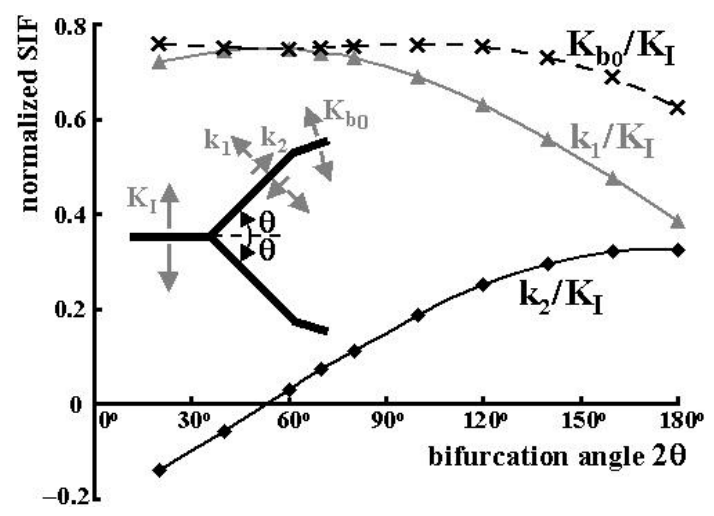

Figura 2. Normalized SIF for symmetrically and asymmetrically bifurcated cracks.

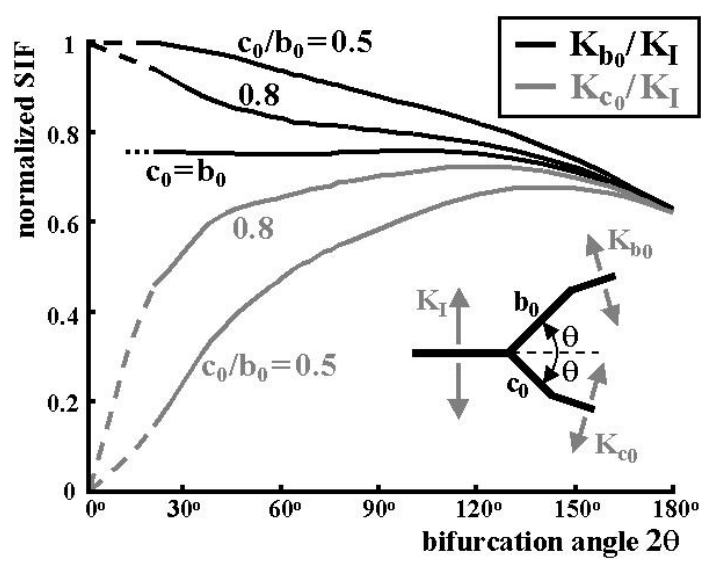

Figura 3. Normalized equivalent SIF for symmetrically and asymmetrically bifurcated cracks.

the propagation behavior immediately after the bifurcation event.

Figure 3 shows the FE results for the equivalent SIF $\mathbf{K}_{\mathbf{b} 0}$ and $\mathbf{K}_{\mathbf{c} 0}$ of the longer and shorter branches respectively (normalized by the Mode I SIF $\mathbf{K}_{\mathbf{I}}$ of the straight crack) of both symmetrically and asymmetrically bifurcated cracks. Note a marked increase in the SIF $\mathbf{K}_{\mathbf{b} 0}$ of the larger branch (and decrease in $\mathbf{K}_{\mathbf{c} 0}$ of the 

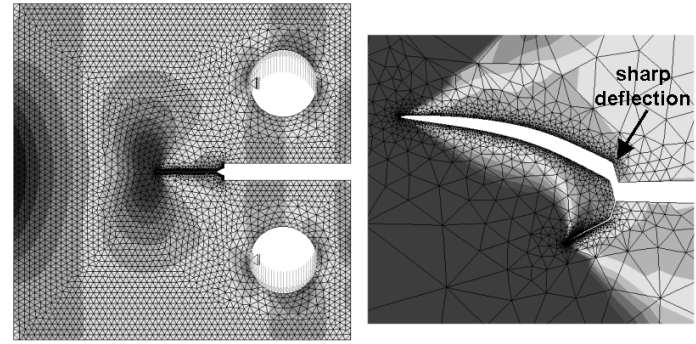

Figura 4. Propagation simulation of a bifurcated crack on a CT specimen (left), with a close-up of the two original I I $\mu \mathrm{m}$ and $10 \mu \mathrm{m}$ branches with angle $2 \theta=150^{\circ}$ (right).

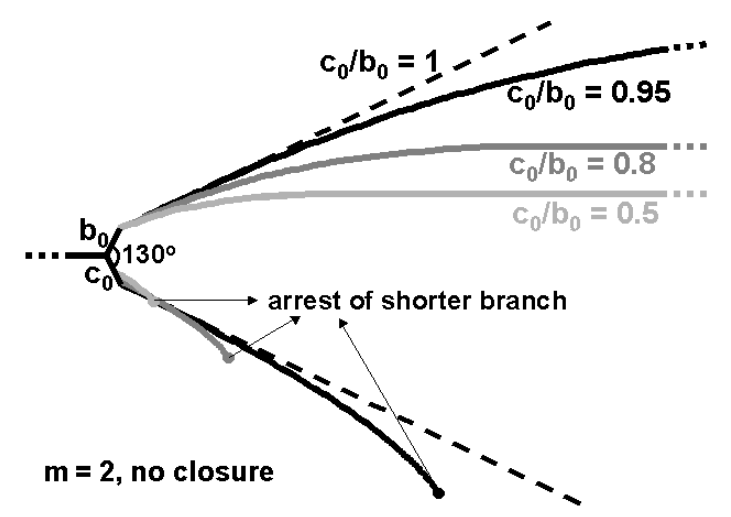

Figura 5. Bifurcated crack paths for several $\mathbf{c}_{\mathbf{0}} / \mathbf{b}_{\mathbf{0}}$ ratios.

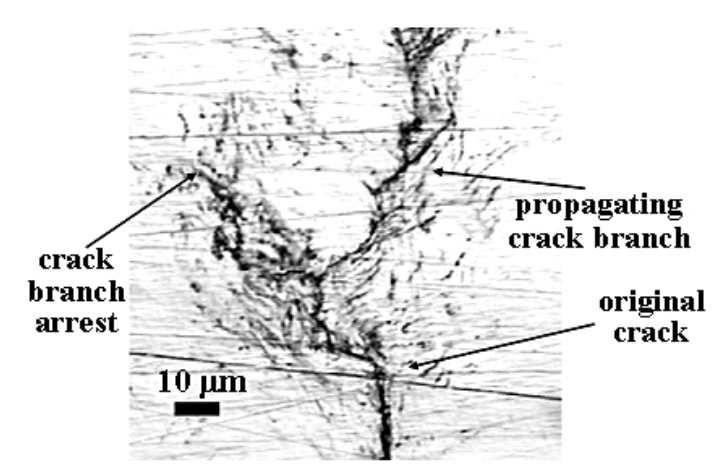

Figura 6. Crack branching on an SAE 4340 ESE(T) specimen.

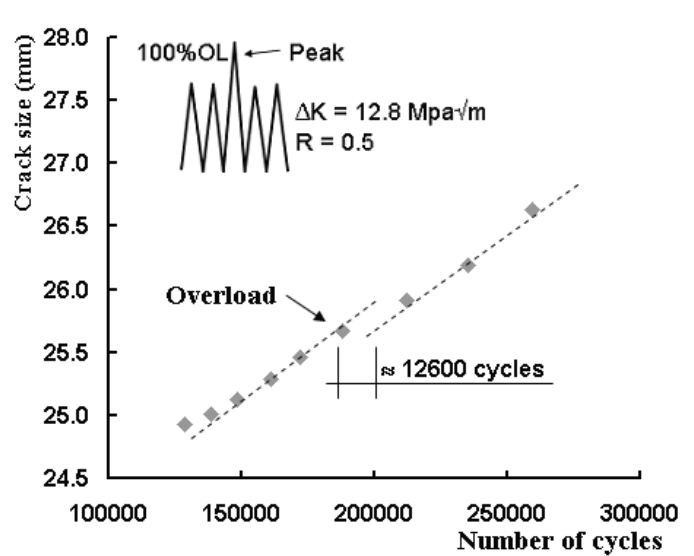

Figura 7. Fatigue crack growth retardation after a $100 \%$ overload, $\mathbf{R}=\mathbf{0 . 5}$. shorter one) if compared to the symmetrically branched solutions. As the length difference between both branches increases, it is expected that the propagation rate of the shorter one is reduced until it arrests, after which the larger branch will dominate. This shielding effect of the longer branch over the shorter one is larger for small bifurcation angles, typically below $120^{\circ}$ (see Fig. 3).

The FE-obtained results shown in Fig. 3 are used to fit empirical equations to the SIF $\mathbf{K}_{\mathrm{b} 0}$ and $\mathbf{K}_{\mathrm{c} 0}$ of the longer and shorter branches, resulting in:

$$
\begin{aligned}
& \frac{K_{b 0}}{K_{I}}=0.75+(1-\sin \theta) \cdot\left(1-\frac{c_{0}}{b_{0}}\right), \\
& \frac{K_{c 0}}{K_{I}}=0.75-(1-\sin \theta) \cdot\left(1-\frac{c_{0}}{b_{0}}\right)
\end{aligned}
$$

The above equation generates errors smaller than $2 \%$ for $40^{\circ} \notin 2 \theta \notin 168^{\circ}$ and $0.7 £ c_{0} / b_{0} \notin$ I.0. In the next section, further FE analyses are conducted to evaluate the subsequent propagation behavior of these bifurcated cracks.

\section{PROPAGATION OF BRANCHED CRACKS}

The growth of branched cracks is studied in the Quebra2D program using the same $C(T)$ specimen described before. A fixed crack growth step of $\Delta \mathbf{b}=3 \mu \mathrm{m}$ (or I $\mu \mathrm{m}$ during the first propagation steps) is considered for the propagation of the longer branch $\mathbf{b}$. This growth step is calculated in the direction defined by the $\sigma_{\theta \max }$ criterion. Due to the differences in the crack growth rate, a growth step $\Delta \mathbf{c}$ smaller than $\Delta \mathbf{b}$ is expected for the shorter branch. This smaller step is obtained assuming a crack propagation law that models the first two growth phases,

$$
\frac{d a}{d N}=A \cdot\left(\Delta K-\Delta K_{t h}\right)^{m}
$$

where $\mathbf{A}$ and $\mathbf{m}$ are material constants and $\Delta \mathbf{K}_{\mathrm{th}}$ is the propagation threshold. If $\Delta \mathbf{K}_{b}$ and $\Delta \mathbf{K}_{c}$ are respectively the equivalent stress intensity ranges of the longer and shorter branches, then the growth step $\Delta \mathbf{c}$ of the shorter branch $\mathbf{c}$ should be

$$
\Delta c=\Delta b \cdot\left(\frac{\Delta K_{c}-\Delta K_{t h}}{\Delta K_{b}-\Delta K_{t h}}\right)^{m}
$$

Figure 4 shows the contour plots of the stress in the load direction axis and propagation results for a bifurcated crack with angle $\mathbf{2} \boldsymbol{\theta}=150^{\circ}$, obtained from the FE analysis. In this figure, the deformations are highly amplified to better visualize the crack path. Note that the crack path deviates from the original branch angles, 


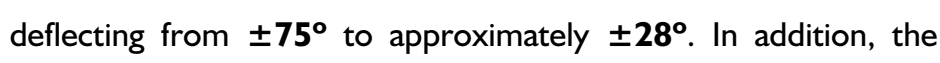
originally shorter branch arrests after propagating to (only) $39 \mu \mathrm{m}$, while the longer branch returns to the pre-overload growth direction and SIF (even though the subsequent crack growth plane may be offset from the pre-overload one, see Fig. 4). Other propagation paths obtained from the FE analyses are shown in Fig. 5 , considering bifurcated cracks with $2 \theta=130^{\circ}$ and $\mathbf{c}_{\mathbf{0}} / \mathbf{b}_{\mathbf{0}}=\{0.5$, $0.8,0.95,1\}$, and a material with $\mathbf{m}=2$.

\section{EXPERIMENTAL RESULTS}

To validate the proposed approach, experiments are performed on Eccentrically-loaded Single Edge Crack Tension specimens $\operatorname{ESE}(T)$ made from an annealed SAE $\mathbf{4 3 4 0}$ alloy steel with yield strength $S_{Y}=377 \mathrm{MPa}$, ultimate strength $\mathbf{S}_{\mathbf{U}}=$ 660MPa, Young modulus E $=205 \mathrm{GPa}$, and reduction in area RA $=\mathbf{5 2 . 7} \%$, and with the analyzed weight percent composition shown in Table I. The tests are performed with a baseline stress intensity range $\Delta \mathbf{K}_{\mathbf{l}}=\mathbf{1 2 . 8} \mathrm{M} \sqrt{ } \mathbf{P a} \div \mathbf{m}$ and $\mathbf{R}=\mathbf{0 . 5}$. Figure 6 shows the measured paths of a branched crack induced by a $\mathbf{5 0 \%}$ overload when the crack length was $\mathbf{a}=\mathbf{2 5 . 5 5} \mathbf{~ m m}$.

Figure 7 shows the retardation effect induced by the bifurcation, leading to approximately 12,600 delay cycles along a process zone of about $\mathbf{0 . 3} \mathbf{m m}$. No closure effects were measured either before or after the overload, because the opening load always remained below the minimum value of the applied load range. Therefore, it can be concluded that the measured retardation effect cannot be explained by crack closure. In fact, the bifurcation event even reduced the closure level by $\mathbf{2 5} \%$ due to the increased compliance caused by the crack branches. Clearly, retardation effects associated with a reduction in the crack opening load would be incompatible with any retardation model based on crack closure. It is implied then that bifurcation is the dominant retardation mechanism.

The measured initial branch lengths are approximately $b_{0}=20 \mu \mathrm{m}$ and $c_{0}=16 \mu \mathrm{m}$, with a bifurcation angle $2 \theta=150^{\circ}$. The material is modeled using Equation (2) with crack growth constants $\mathbf{A}=\mathbf{9} \cdot 10^{-11} \mathrm{~m} /$ cycle and $\mathbf{m}=\mathbf{2 . 2}$, and a propagation threshold $\Delta \mathbf{K}_{\text {th }}=$ 3.8MPa $\sqrt{ } \mathbf{m}$, all measured under $\mathbf{R}=\mathbf{0 . 5}$.

For the baseline stress intensity range $\Delta \mathbf{K}_{\mathbf{l}}=$ I 2.8MPa $\sqrt{ } \mathrm{m}$, it is found from the FE calculations that $\Delta K_{b 0}=9.69$ and $\Delta K_{c 0}=9.5 \mathrm{IMPa} \sqrt{ } \mathrm{m}$. Since both ranges are greater than $\Delta \mathbf{K}_{\mathrm{th}}(\mathbf{R}=\mathbf{0 . 5})$ $=3.8 \mathrm{MPa} \vee \mathrm{m}$, both branches are expected to start propagating, as verified experimentally. The number of cycles spent during the propagation in the retardation region is then calculated by integrating the $\mathbf{d a} / \mathbf{d N}$ equation along the longer crack branch, considering the FE-obtained reduction in the SIF. This calculation results in 12,024 cycles, which is very close to the measured 12,600 delay cycles. In addition, the process zone size (beyond which the retardation effect disappears) calculated using Quebra2D and $\mathrm{ViDa}$ is $307 \mu \mathrm{m}$, matching very well the measured

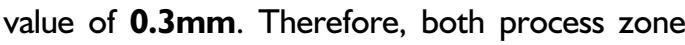
size and number of delay cycles are well estimated using the proposed FE approach.

\section{CONCLUSIONS}

In this work, a specialized FE program was used to calculate the propagation path of bifurcated cracks, which can cause crack retardation or even arrest. It was found that crack deflection processes alone can significantly reduce the stress intensity factors (SIF) and therefore the propagation rates, leading to crack retardation or even arrest. It was shown that the shorter branch of bifurcated cracks eventually arrests as the longer one returns to the pre-overload propagation conditions. Life assessment calculations were performed using a local approach program to estimate the number of delay cycles caused by crack bifurcation. The proposed approach was validated experimentally, allowing for a better understanding of the influence of crack deflection in the propagation life of structural components. From these results, it was found that crack bifurcation can provide an alternate mechanistic explanation for overload-induced crack retardation, in special to explain retardation under high $\mathbf{R}$ ratios, where no crack closure would be detected.

\section{REFERENCES}

LANKFORD, J.; DAVIDSON, D.L. The effect of overloads upon fatigue crack tip opening displacement and crack tip opening/closing loads in aluminum alloys. In Advances in Fracture Research, New York, v. 2, p. 899-906, 1981. 
SURESH, S. Crack deflection: implications for the growth of long and short fatigue cracks. Metallurgical Transactions A, Warrendale, PA, v. I4A, n. I2, p. 2375-85, December 1983.

KOSEC, B.; KOVACIC, G.; KOSEC, L. Fatigue cracking of an aircraft wheel. Engineering Failure Analysis, New York, v. 9, n.5, p. 603-9, Oct. 2002.

SURESH, S. Micromechanisms of fatigue crack growth retardation following overloads. Engineering Fracture Mechanics, New York, v. 18, n. 3, p. 577-93, 1983.

MIRANDA, A.C.O.; MEGGIOLARO, M.A.; CASTRO, J.T.P.; MARTHA, L.F.; BITTENCOURT, T.N. Fatigue crack propagation under complex loading in arbitrary 2D geometries. In: Braun, A.A.; McKeighan, P.C.; Lohr, R.D. (Ed.). Applications of automation technology in fatigue and fracture testing and analysis. West Conshohocken, PA: American Society for Testing and Materials, 2002. V.4, p. I20-I46. (ASTM Special Technical Publication, STP I4II)

MEgGIOLARO, M. A.; CASTRO, J. T. P. ViDa 98 - Danômetro Visual para Automatizar o Projeto à Fadiga sob Carregamentos Complexos. Journal of Brazilian Society of Mechanical Sciences (RBCM), Rio de Janeiro, v. 20, n. 4, p. 666-685, 1998.

PIPPAN, R.; FLECHSIG, K.; RIEMELMOSER, F. O. Fatigue crack propagation behavior in the vicinity of an interface between materials with different yield stresses. Materials Science and Engineering A, New York, v. 283, n. I-2, p. 225-33, May 2000. 